\title{
Evaluation of Erectile Function and Quality of Life in Patients Undergoing Methadone Maintenance Treatment
}

\author{
Sava Petrov ${ }^{1, ~ *, ~ M a r i a ~ O r b e t z o v a ~}{ }^{1}$, Yanko Iliev ${ }^{2}$, Doychin Boyadzhiev ${ }^{3}$, Lyuba Hadzhiyska ${ }^{4}$, \\ Stefan Popov ${ }^{5}$ \\ ${ }^{1}$ Second Department of Internal Disease, Section of Endocrinology and Metabolic Diseases, Medical University, Plovdiv, Bulgaria \\ ${ }^{2}$ Department of Clinical Toxicology, Medical University, Plovdiv, Bulgaria \\ ${ }^{3}$ University of Plovdiv, Plovdiv, Bulgaria \\ ${ }^{4}$ Private Psychiatric Practice Philippopolis Ltd., Plovdiv, Bulgaria \\ ${ }^{5}$ Department of Psychiatry, Medical University, Plovdiv, Bulgaria
}

Email address:

sava86@abv.bg. (S. Petrov)

${ }^{*}$ Corresponding author

\section{To cite this article:}

Sava Petrov, Maria Orbetzova, Yanko Iliev, Doychin Boyadzhiev, Lyuba Hadzhiyska, Stefan Popov. Evaluation of Erectile Function and Quality of Life in Patients Undergoing Methadone Maintenance Treatment. Science Journal of Clinical Medicine.

Vol. 6, No. 5, 2017, pp. 68-73. doi: 10.11648/j.sjcm.20170605.11

Received: January 26, 2017; Accepted: February 10, 2017; Published: October 18, 2017

\begin{abstract}
The controversial data for erectile function and quality of life of patients undergoing methadone maintenance treatment (MMT) and lack of questionnaire-based studies, providing information about these bio-psycho-social issues, in Bulgaria motivated the investigators to examine the frequency of erectile dysfunction among patients on methadone maintenance treatment, and to identify quality of life among these subjects. For these needs cross-sectional, observational with no intervention, case-control, questionnaire-based study was performed which included participants from 18 to 40 years of age undergoing MMT for at least six months and clinically healthy people. A total of 91 patients from 5 clinical programs for MMT in Bulgaria took part in the study and 27 clinically healthy people from the same age and without a history of drug abuse, psychiatric and somatic diseases which served as a control group. All participants signed informed consent. For evaluating erectile function International Index of Erectile Function survey was used. SF 36 v.2 quality of life survey was used for assessing the quality of the participants. When comparing results of the quality of life survey in Patient and Control group significant differences were found in all of the components of the survey $(p<0.05)$ with lower results in the Patient group. When analysing results from the IIEF survey significantly lower total scores were present for all components of the survey in the patient as compared to the group of healthy men $(\mathrm{p}<0.05)$.
\end{abstract}

Keywords: Erectile Function, Methadone, IIEF, Erectile Dysfunction, Quality of Life, SF 36

\section{Introduction}

Substance use disorder is a medical condition with a complex bio-psycho-social genesis which causes multifactorial damage to the normal functioning of individuals. Opioids, with main representative - heroin, are the most common substances associated with problematic use among drug abusers [1]. A multicenter approach is required for the treatment process. Opioid-use disorders resulted in 51 000 deaths worldwide in 2013, up from 18000 deaths in 1990 [2].
The use of methadone maintenance treatment (MMT) for opioid dependence began in the United States and has proved to be an effective intervention in controlling drug use among heroin addicts [3, 4]. With the implementation of the National Programme for Prevention, Treatment and Rehabilitation of Drug Addiction in Bulgaria, a network of MMT programs was created [5].

Methadone is a synthetic, long-acting agonist of the $\mu$ receptors. It has morphine-like effects, such as analgesia, euphoria, sedation, respiratory depression, miosis, bradycardia and physical dependence. It was developed in 
Germany in 1937 by the scientists Max Bockmühl and Gustav Ehrhart, working for the German chemical conglomerate IG Farberindustrie [6].

The chronic use of opioids including methadone in men leads to symptoms such as delayed ejaculation, erectile dysfunction and significant reduction of sexual libido [7]. Accordingly, in men seeking treatment for opioid dependence, the prevalence of sexual dysfunction (SD) was significantly higher in comparison with healthy control subjects [8]. Estimates of SD among men on methadone differ widely, ranging from $16 \%$ to $53 \%$ [9-11]. On the other hand, a more recent study [12] shows a decrease in the severity of SD in association with methadone maintenance initiation. A majority of the studies are based on a small number of patients, and very few researchers used validated questionnaires like the International Index of Erectile Function (IIEF) to assess erectile dysfunction (ED). This fact highlights an important deficiency in this area of research. Most of the prominent foreign sources, the prestigious pharmacological and pathological texts, sites and essays show different frequencies for erectile dysfunction (ED); in the meantime, there is no available statistics of erectile dysfunction in patients on MMT in Bulgaria.

In recent years, there has been an increased interest in health status and life quality, especially of the addicts [13]. The results of various studies indicate that the quality of life of addicts is lower than that of normal people [14]. Some studies have also shown that methadone and buprenorphine maintenance treatments have had positive effects on the life quality of the addicts [15]. It has been shown that chronic maintenance treatment with Methadone has a positive effect on improving the quality of life from baseline $[16,17]$.

The controversial data for erectile function and quality of life of patients undergoing MMT and lack of questionnairebased studies, providing information about these bio-psychosocial issues, in Bulgaria motivated the investigators of doing this research.

AIMS: The aims of the present study were to examine the frequency of ED among MMT patients, and to identify quality of life among these subjects.

\section{Methods}

A cross-sectional, observational with no intervention, case-control, questionnaire-based study was performed. The Ethical Review Board of Medical University of Plovdiv gave ethical approval for the study. A structured interview was administered by clinical staff. The interview included questions on anthropometrics, drug use and sexual behaviour, concomitant somatic diseases, presence of transmissible infections such as human immunodeficiency virus (HIV), hepatitis $\mathrm{B}$ virus (HBV) and hepatitis $\mathrm{C}$ virus (HCV). Subjects declaring a stable relationship with a partner (in the last 6 months) were investigated. In addition to the socialhealth survey, two questionnaires were applied: the International Index of Erectile Function (IIEF) covering five domains of male sexual function: erectile function $(\mathrm{EF})$, intercourse satisfaction (IS), orgasm, desire (OD), overall satisfaction (OS) [18]. The EF domain ranges from 1 to 30 and depending on the score the following grades can be differed: 1-10: Severe Erectile Dysfunction; 11-16: Moderate dysfunction; 17-21: Mild to moderate dysfunction; 22-25: Mild dysfunction - slight degree; 26-30: No dysfunction. For other domains the higher the score the less the dysfunction [19]. The quality of life (QOL) SF36 v.2 questionnaire translated and validated for use in the Bulgarian language [20], assesses the quality of life in eight different components: physical functioning (PF), role-physical (RP), bodily pain (BP), general health (GH ), vitality (VT), social functioning (SF), role-emotional (RE), mental health $(\mathrm{MH})$. It provides a summarized evaluation both for physical (PCS) and mental components (MCS) [21, 22]. The assessment of each component ranges from 0 to 100 , with scores of 100 indicating the best condition. The evaluation system is based upon a representative sample of the population and the questionnaire can be used to assess the physical and mental status of the participants in relation to the general population - norm-based scores (NBS).

Total number of the participants in the study was 118 people aged between 18 and 40 years. A total of 91 patients were from 5 clinical programs for MMT in Bulgaria took part in the study and 27 clinically healthy people from the same age and without a history of drug abuse, psychiatric and somatic diseases which served as a control group. The mean age of the participants was $31.3( \pm 4.2)$ years for the Patients group and $27.3( \pm 3.8)$ years for the healthy controls. A hundred of them performed the SF 36 survey divided into two groups - 76 patients undergoing chronic MMT and 24 controls. The IIEF questionnaire-based study comprised of 97 participants: 74 patients and 23 controls. 79 participants performed both questionnaires - IIEF and SF-36.

Inclusion criteria for Patients' group: The patients were addicts who used MMT for withdrawal with a stable sexual partnership.

Inclusion criteria for Control group: No history of drug use and stable sexual partnership.

Exclusion criteria for both groups: Persons who had a history of erectile dysfunction and took drugs that suppressed erection such as diuretics, anti-cholinergic agents and antipsychotics, and patients with chronic diseases like diabetes mellitus and end-stage renal disease were excluded. Also, the participants who had a history of atherosclerosis based on cardio-vascular problems such as myocardial infarction, cerebrovascular accident and peripheral vessels diseases, accompanying physical or mental disorders were excluded from the study, because these problems can cause erectile dysfunction and deteriorating quality of life.

All participants signed informed consent.

The administration of methadone was oral, every day. The Control and Patients' group were body mass index (BMI) matched with no difference between the groups by these criteria.

A total of five Methadone maintenance treatment programs with opiate agonists and agonists-antagonists at 
four regional cities in Bulgaria - Sofia, Plovdiv, Pazardjik, Stara Zagora, were included in the study. Patient group was subdivided into three subgroups based on the mean and SD of the following three factors: dose, duration of treatment, and exposure to heroin before first methadone treatment. The low subgroup had one of the three factors below one SD of the mean (i.e., < mean-SD); medium subgroup had one of the three factors between one $\mathrm{SD}$ (i.e., mean $\pm \mathrm{SD}$ ); the high subgroup had one of the three factors above one SD of the mean (i.e., > mean+SD). Prevalence of $\mathrm{HBV}$ and $\mathrm{HCV}$ was taken into consideration using history of concomitant diseases from medical documentation available in the Methadone Programs for each patient.

Comparisons of survey results were performed between patients and healthy controls. The survey forms of IIEF and SF-36 QOL in Bulgarian language are officially translated and validated and the software and key for processing the results were presented by courtesy of Pfizer Patient Reported Outcomes and OptumTM, which possesses the right to distribute and license the surveys [23].

For statistical analyses we used SPSS Inc., IBM SPSS Statistics v. 21.0. The statistical methods used in the investigations were Descriptive statistics, Independent Samples T-Test, Fisher's exact test ANOVA, Post-Hoc analysis, Mann-Whitney U test, Linear Regression.

\section{Results}

The mean daily dose of Methadone used for maintenance treatment of the patients was $9.8( \pm 4.0) \mathrm{ml} /$ daily or 98 $\mathrm{mg}$ /daily. The average duration of exposure to methadone for the study group was $34( \pm 24)$ months and the mean duration of exposure to heroin prior starting treatment with methadone was $6.54( \pm 3.4)$ years.

Comparisons of domains of QOL - SF 36 survey between the Patients group and Control group showed that there were significant differences in all of the components of the survey $(\mathrm{P}<0.05)$. The patients group showed significantly lower results in all eight domains of SF 36 survey as well as in correlated Physical and Mental Summary Scores PCS and MCS - Table 1.

Table 1. Number of participants and score of the components of the $Q O L$ survey.

\begin{tabular}{|c|c|c|c|c|c|}
\hline & Participants & $\mathbf{N}$ & Mean & Std. Deviation & \\
\hline \multirow{2}{*}{ PF } & Patients & 76 & 89.74 & 4.24 & \multirow{2}{*}{$0.000 * * *$} \\
\hline & Controls & 24 & 100 & 0.00 & \\
\hline \multirow{2}{*}{ RP } & Patients & 76 & 82.07 & 8.56 & \multirow{2}{*}{$0.006^{* *}$} \\
\hline & Controls & 24 & 96.09 & 3.37 & \\
\hline \multirow{2}{*}{ BP } & Patients & 76 & 75.50 & 10.51 & \multirow{2}{*}{$0.027 *$} \\
\hline & Controls & 24 & 87.83 & 4.59 & \\
\hline \multirow{2}{*}{ GH } & Patients & 76 & 61.88 & 9.38 & \multirow{2}{*}{$0.000 * * *$} \\
\hline & Patients & 24 & 87.46 & 4.52 & \\
\hline \multirow{2}{*}{ VT } & Patients & 76 & 56.99 & 9.62 & \multirow{2}{*}{$0.000 * * *$} \\
\hline & Controls & 24 & 76.56 & 7.24 & \\
\hline \multirow{2}{*}{ SF } & Patients & 76 & 78.45 & 10.28 & \multirow{2}{*}{$0.015^{*}$} \\
\hline & Controls & 24 & 92.19 & 6.58 & \\
\hline \multirow{2}{*}{ RE } & Patients & 76 & 79.16 & 10.64 & \multirow{2}{*}{$0.002 * *$} \\
\hline & Controls & 24 & 95.83 & 4.48 & \\
\hline \multirow{2}{*}{ MH } & Patients & 76 & 64.80 & 9.53 & \multirow{2}{*}{$0.000 * * *$} \\
\hline & Controls & 24 & 79.58 & 6.54 & \\
\hline \multirow{2}{*}{ PCS } & Patients & 76 & 53.53 & 6.32 & \multirow{2}{*}{$0.000 * * *$} \\
\hline & Controls & 24 & 58.76 & 2.10 & \\
\hline \multirow{2}{*}{ MCS } & Patients & 76 & 45.27 & 10.52 & \multirow{2}{*}{$0.001 * *$} \\
\hline & Controls & 24 & 53.14 & 7.12 & \\
\hline
\end{tabular}

Sig. $(2$-tailed $) *(\mathrm{p}<0.05),{ }^{* *}(\mathrm{p}<0.01) * * *(\mathrm{p}<0.001)$

In 45 of patients were with a past medical history of HCV. Compared by presence of HCV no significant differences were found in any of the domains of the survey between two groups.

When analyzing results from the IIEF survey, using MannWhitney $U$ test, we established significantly lower total scores on the scale for all components of the survey in the patients as compared to the group of healthy men $(\mathrm{P}<0.05)$ : EF $(23.81 \pm 4.98$ vs. $29.27 \pm 0.77)$; OF $(8.04 \pm 2.1$ vs. 9.14 $\pm 1.36)$; SD (7.16 \pm 1.62 vs. $9.05 \pm 0.95)$; IS (10.09 $\pm 3.10 v s$. $13.05 \pm 1.62)$; OS $(7.18 \pm 1.94$ vs. $9.23 \pm 0.87)$ - figure 1 .

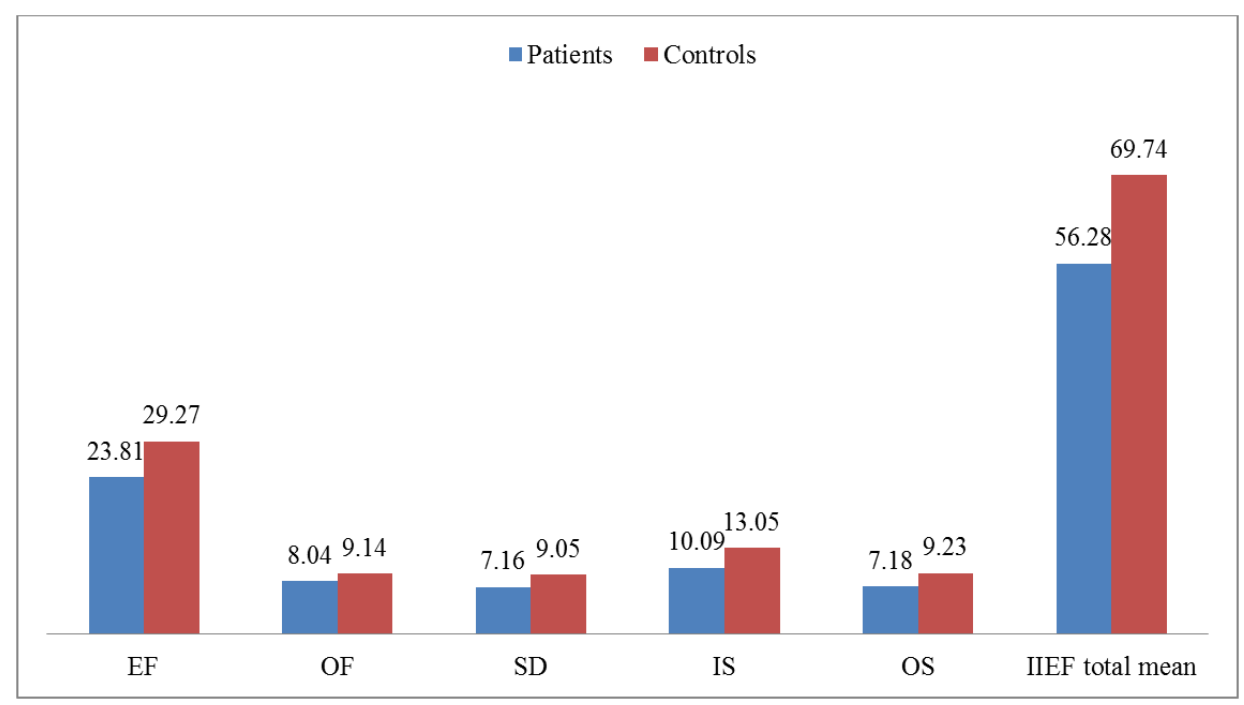

Figure 1. Scoring of IIEF in Patients and Controls. 
The total means score criterion EF (23.81) in the investigated group of patients indicated ED of slight degree.

Accordingly to IIEF scoring system erectile function domain qualifies erectile dysfunction (ED) in five grades: No erectile dysfunction with score between $26-30$ points; Mild dysfunction: 22-25 points; Mild to Moderate dysfunction: 17-21 points; Moderate dysfunction: 11-16 points and Severe Erectile Dysfunction with 1-10 points. Patients' distribution by EF domain is shown in table 2 .

Table 2. Distribution of the patients by EF domain scoring grades.

\begin{tabular}{lllll}
\hline No ED n & Mild ED n & Mild to Moderate ED n & Moderate ED n & Severe ED n \\
\hline $30(40.5 \%)$ & $26(35.1 \%)$ & $12(16.2 \%)$ & $3(4.1 \%)$ & $3(4.1 \%)$ \\
\hline
\end{tabular}

Difference in mean daily dose of MMT was found between the groups. Patients with Mild ED (11.56 \pm 3.9 $\mathrm{ml} /$ daily) were treated with significantly higher daily dose during their MMT compared with those with No ED (8.88 $\pm 3.88 \mathrm{ml} /$ daily) $(\mathrm{p}<0.009, \mathrm{t}=-2.72)$.

When using bivariate analysis significant correlations were found between domains of the survey QOL and the following factors: dose, duration of MMT, duration of heroin exposure (DHE) $(\mathrm{p}<0.05)$.

Influence of factors of methadone exposure: duration of MMT, daily dose of Methadone and DHE prior treatment on quality of life was analyzed by using multivariate analysis. The factor with greatest influence on quality of life is mean daily dose of Methadone treatment. It correlates strong with both PCS $\left(B=0.915, r^{2}=0.84, p<0.001\right)$ and MCS $(B=0.890$, $\left.r^{2}=0.79, p<0.001\right)$ domain. EF was taken in consideration as a factor influencing quality of life. Significant relationship exists between erectile function and PCS $\left(B=0.964, r^{2}=0.93\right.$, $\mathrm{p}<0.001)$ and $\operatorname{MCS}\left(\mathrm{B}=0.984, \mathrm{r}^{2}=0.97, \mathrm{p}<0.001\right)$ domain.

\section{Discussion}

This study rated the effect of MMT on patients from 5 programs on subjective function, well-being, erectile function and the influence of the different factors on QOL. In this study the key results indicated that patients on MMT experienced a marked decrease in scores on all scales, as well as the PCS and MCS of the SF-36-survey. This is wellknown fact and many other authors had pointed it out before $[24,25,26,27]$. Chronic MMT improves quality of life and reduces crime events among heroin addicted patients [28]. Impossibility of performing longitudinal rather crosssectional design is the greatest shortcoming of this study so we could not evaluate the positive effects of MMT. It must be taken in consideration that comorbid psychiatric disorders are among the difficulties faced by patients with MMT that negatively impact quality of life [29].

In our study we tried to evaluate in details the influence of factors of MMT - mean daily dose, duration of MMT and also duration of heroin abuse before initiating MMT, on different domains of both questionnaires. A significant relationship was observed between quality of life, dose of MMT and duration of heroin exposure. From all factors of opioid exposure the factor with the greatest negative influence of quality of life is the mean daily dose of MMT. Erectile function is also negatively influenced most by mean daily dose of MMT hence specialist working with heroin addicted patients and conducting MMT should take in consideration this fact and should use the lowest possible dose of methadone.

From the multivariate regression analysis it becomes clear that erectile function renders the greatest influence on quality of life. People undergoing chronic MMT are of young age with a high comorbidity [30], infected with HBV, HBC, HIV [31]. It is well-known that the majority of patients undergoing chronic MMT experience problems with erectile function, endocrine disturbances and reproduction difficulties $[32,33,34]$. Analysis of the results from our study definitely proves that the chronic use of methadone leads ED which is in unison with other authors' studies $[35,36]$. The chronic exposure to methadone results in impairment of all components for assessment of erectile function included in the international survey IIEF. The pioneer data in our study is that erectile function imposes the heaviest influence on quality of life. Treatment of erectile dysfunction is one of the key moments in improving quality of life. A multidisciplinary approach should be applied in the attempt of solving problems of the opiate abusers, which is a guarantee of success and the key to improving the quality of life of the target patients.

\section{Conclusions}

The result from this study clearly indicate that all the factors related to sexual function such as erectile function, sexual desire, orgasm, sexual and overall satisfaction have decreased considerably. This study proved that erectile dysfunction has a high prevalence in male patients undergoing MMT. The findings overall suggest that patients undergoing chronic MMT presented significant lower results in all domains of the survey for quality of life compared with Controls. When evaluating factors of methadone exposure the main factor that influences both PCS and MCS domains of SF 36 survey is mean daily dose of methadone. Not only do these findings highlight the importance of addressing erectile function and of providing support for physical and social well-being during treatment, but they serve as a reminder that patients undergoing MMT are vulnerable to many of the same situations and conditions as those without a opioid dependance. Erectile function is in a strong correlation with both PCS and MCS domains of SF 36 survey and renders a great influence of quality of life among young men. 


\section{Acknowledgements}

The work is funded by $\mathrm{PhD}$ educational grant from Medical University of Plovdiv.

\section{References}

[1] Nutt, D.; King, L. A.; Saulsbury, W.; Blakemore, C. "Development of a rational scale to assess the harm of drugs of potential misuse". The Lancet 2007; 369 (9566): 10471053.

[2] GBD 2013 Mortality and Causes of Death, Collaborators: Global, regional, and national age-sex specific all-cause and cause-specific mortality for 240 causes of death, 1990-2013: a systematic analysis for the Global Burden of Disease Study 2013." Lancet 2014; 385: 117-171.

[3] Vemter A, Buning E: Information for policymakers on the effectiveness of substitution treatment for opiate dependence. Euro Methwork 2003.

[4] Jamieson BLA, Inc. Literature Review: Methadone Maintenance Treatment. The Office of Canada's Drug Strategy, Health Canada 2002.

[5] Национална програма за развитие на лечебна система от метадонови поддържащи програми в Р. България. available at: http://www.ncn-bg.org/.

[6] Herman J., Sharon S., John L.: Methadone Maintenance Treatment (MMT): A Review of Historical and Clinical Issues. Mt Sinai J Med 2000. Oct-Nov; 67 (5-6): 347-64.

[7] Bang-Ping J: Sexual dysfunction in men who abuse illicit drugs: a preliminary report. J Sex Med 2009; 6: 1072-1080.

[8] Venkatesh K, Mattoo SK, Grover S: Sexual dysfunction in men seeking treatment for opioid dependence: a study from India. J Sex Med 2014; 11: 2055-2064.

[9] Quaglio G, Lugoboni F, Pattaro C. Erectile dysfunction in male heroin users receiving methadone and buprenorphine maintenance treatment. Drug Alcohol Depend 2008; 94: 12-8.

[10] Hallinan R, Byrne A, Agho K, McMahon C, Tynan P, Attia J. Erectile dysfunction in men receiving methadone and buprenorphine maintenance treatment. J Sex Med 2008; 5: 684-92.

[11] Brown R, Balousek S, Mandt M, Fleming M. Methadone maintenance and male sexual dysfunction. J Addict Dis 2005; 24: 91-106.

[12] Zhang M, Zhang H, Shi CX, McGoogan JM, Zhang B, Zhao, L, Zhang M, Rou K, Wu Z: Sexual dysfunction improved in heroin-dependent men after methadone maintenance treatment in Tianjin, China. PLoS One 2014; 9 (2): e88289.

[13] Amiri M, Khosravi A, Chaman R. Drug Abuse Pattern and High Risk Behaviors among Addicts in Shahroud County of Semnan Province, Northeast Iran in 2009. J Res Health Sci. 2010; 10 (2): 104-9.

[14] Bizzarri J, Rucci P, Vallotta A, Girelli M, Scandolari A, Zerbetto E, et al. Dual diagnosis and quality of life in patients in treatment for opioid dependence. Subst. Use Misuse. 2005; 40 (12): 1765-76.
[15] Maremmani I, Pani PP, Pacini M, Perugi G. Substance use and quality of life over 12 months among buprenorphine maintenance-treated and methadone maintenance-treated heroin-addicted patients. J Subst Abuse Treat. 2007; 33 (1): 91-8.

[16] Wang PW, Lin HC et all. Comparison of outcomes after 3month methadone maintenance treatment between heroin users with and without HIV infection: a 3-month follow-up study. Harm Reduct J. 2015; 12: 13.

[17] Chang, K.-C., \& Lin, C.-Y. Effects of publicly-funded and quality of life on attendance rate among methadone maintenance treatment patients in Taiwan: an 18-month follow-up study. Harm Reduction Journal. 2015; 12, 40.

[18] Rosen RC, Riley A, et all. The international index of erectile function (IIEF): a multidimensional scale for assessment of erectile dysfunction. Urology. 1997 Jun; 49 (6): 822-30.

[19] Cappelleri JC, Siegel RL, Osterloh IH, Rosen RC. Relationship between patient self-assessment of erectile function and the erectile function domain of the International Index of Erectile Function. Urology. 2000; 56: 477-481.

[20] John E. Ware. SF-36 Health Survey Update SPINE Volume 25, Number 24, 200 pp 3130-3139.

[21] Ware J. Gandek B. Overview of the SF-36 Health Survey and the International Quality of Life Assessment (IQOLA) Project. J Clin Epidemiol. 199851 (11): 903-912.

[22] Su, C.-T., Ng, H.-S., Yang, A.-L., \& Lin, C.-Y. Psychometric evaluation of the Short Form 36 Health Survey (SF-36) and the World Health Organization Quality of Life Scale Brief Version (WHOQOL-BREF) for patients with schizophrenia. Psychological Assessment, 201426 (3), 980-989.

[23] Available at https://www.pfizerpatientreportedoutcomes.com/ and

http://www.qualitymetric.com/Portals/0/Uploads/Documents/ Public/QM_Catalog_2011.pdf.

[24] Smith KW, Larson MJ. Quality of life assessments by adult substance abusers receiving publicly funded treatment in Massachusetts. Am J Drug Alcohol Abuse. 2003; 29 (2): 323 35 .

[25] Ryan, CF, \& White, JM. Health status at entry to methadone maintenance treatment using the SF-36 health survey questionnaire. Addiction. 1996; 91, 39-45.

[26] Maremmani I, Pani PP, Pacini M, Perugi G. Substance use and quality of life over 12 months among buprenorphine maintenance-treated and methadone maintenance-treated heroin-addicted patients. J Subst Abuse Treat. 2007; 33 (1): 91-8. doi: 10.1016/j. jsat.2006.11.009.

[27] Rudolf, H., \& Watts, J. Quality of life in substance abuse and dependency. International Review of Psychiatry. 2002; 14, 190-197.

[28] Sun, HM, Li, XY, Chow, EP, Li, T, Xian, Y, Lu, YH, Zhang, L. Methadone maintenance treatment programme reduces criminal activity and improves social wellbeing of drug users in China: A systematic review and meta-analysis. BMJ Open. 2015; 5, e005997.

[29] Teoh Bing Fei J, Yee A, Habil MH. Psychiatric comorbidity among patients on methadone maintenance therapy and its influence on quality of life. Am J Addict 2016 Jan; 25 (1): 49-55. 
[30] Nordmann S, Lions C, Vilotitch A et all. A prospective, longitudinal study of sleep disturbance and comorbidity in opiate dependence (the ANRS Methaville study). Psychopharmacology (Berl). 2016Apr; 233 (7).

[31] Alshomrani AT. Prevalence of human immunodeficiency virus, hepatitis $\mathrm{C}$ virus, and hepatitis $\mathrm{B}$ virus infection among heroin injectors in the central region of Saudi Arabia. Saudi Med J. 2015Jul; 36 (7): 802-6.

[32] Hallinan R, Byrne A, AghoK, McMahonC, Tynan P, Attia J. Erectile dysfunction in men receiving methadone and buprenorphine maintenance treatment. J Sex Med 20085: 684-692.

[33] de la Rosa RE, Hennessey JV. Hypogonadism and methadone: hypothalamic hypogonadism after long-term use of high-dose methadone. Endocr Pract 19962: 4-7.

[34] Cicero TJ. Opiate and opioid modulation of reproductive endocrinology in the male and female: development and pregestational aspects. NIDA Res Monogr 1984 55: 14-23.

[35] Gerra $G$ et all. Sexual Dysfunction in Men Receiving Methadone Maintenance Treatment: Clinical History and Psychobiological Correlates. Eur Addict Res. 2016; 22 (3): 163-75.

[36] Yee A et. all. Sexual Dysfunction in Heroin Dependents: A Comparison between Methadone and Buprenorphine Maintenance Treatment. PLoS One. 2016 Jan 28; 11 (1): $\mathrm{e} 0147852$. 